\title{
EXIGIBILIDADE CONSTITUCIONAL DA SUSTENTABILIDADE NAS CONTRATAÇÕES PÚBLICA: NORMAS TÉCNICAS E GESTÃO DE RISCOS COMO INSTRUMENTOS DE EFICIÊNCIA
}

\author{
Salete Oro Boff* \\ Dionis Janner Leal*
}

\section{Resumo:}

As contratações públicas têm como dever constitucional buscar práticas e aquisições sustentáveis. Mas há pouco uso de ferramentas capazes de alcançar essa dimensão sustentável. A partir dessa verificação, no presente estudo objetiva-se demonstrar que o dever do Estado não dispensa as necessárias ações administrativas, inclusive adoção de práticas de mercado, como a utilização de normas técnicas, a gestão de riscos e o compliance em aquisições sustentáveis. Assim, com o uso dessas ferramentas, tem-se como possível as contratações públicas sustentáveis, com eficiência administrativa e gestão de riscos. O estudo foi desenvolvido utilizando o método dedutivo e a técnica de pesquisa bibliográfica.

Palavras-chave: Compliance; contratação pública; gestão de riscos; normas técnicas; sustentabilidade.

\section{CONSTITUTIONAL REQUIREMENT FOR SUSTAINABILITY IN PUBLIC CONTRACTING: TECHNICAL STANDARDS AND RISK MANAGEMENT AS AN EFFICIENCY INSTRUMENT}

\begin{abstract}
:
Public procurement has a constitutional duty to seek sustainable practices and acquisitions. But there is little use of tools capable of reaching this sustainable dimension. Based on this verification, this study aims to demonstrate that the State's duty does not dispense with the necessary administrative actions, including the adoption of market practices, such as the use of technical standards, risk management and compliance in sustainable acquisitions. Thus, with the use of these tools, sustainable public procurement is possible, with administrative efficiency and risk management. The study was developed using the deductive method and the bibliographic research technique.
\end{abstract}

Keywords: Compliance; public procurement; risk management; technical standards; sustainability

\section{INTRODUÇÃO}

\footnotetext{
* Pós-Doutora em Direito pela UFSC. Doutora em Direito pela UNISINOS. Coordenadora do Programa de Pósgraduação em Direito da Faculdade Meridional - IMED - Mestrado. Grupo de Pesquisa-CNPq Direito, Novas Tecnologias e Desenvolvimento. Grupo de Estudos em Desenvolvimento, Inovação e Propriedade IntelectualGEDIPI. Docente da UFFS. E-mail salete.oro.boff@gmail.com.

* Mestrando em Direito - PPGD - Faculdade Meridional - IMED. Pós-graduado em Direito Público. Membro do Grupo de Estudos em Desenvolvimento, Inovação e Propriedade Intelectual-GEDIPI. Advogado. E-mail: dionislealadv@gmail.com
} 
O Estado enquanto promotor do bem-estar de seus cidadãos (art. $3^{\circ} \mathrm{IV}, \mathrm{CF}$ ) deve zelar por um meio ambiente equilibrado para que as atuais e futuras gerações de seus cidadãos (art. 225, CF) possam usufruir de bens naturais sem aniquilá-lo ou atenuar sua oferta. Para tanto, no exercício de suas funções e na busca de objetivos constitucionais e de interesse público, o Estado e quem lhe faça às vezes deve se valer de instrumentos capazes de melhor executar seus objetivos.

Nesse sentido, na seara das aquisições públicas, comumente utilizada por intermédio de procedimentos licitatórios - ou excepcionalmente, a processos de contratação direta nas exceções legais - é onde a Administração Pública tem poder natural (regulador e econômico) de influenciar a iniciativa privada (mercado privado) a fim de atender seus interesses primários (interesse público) instigando-as a adotar meios de produção de bens de consumo que causem menor impacto ambiental no uso de matéria prima, seja regulando setores de mercado de exploração, seja exigindo apenas produtos que atendam princípios da eficiência e, hodiernamente, da sustentabilidade constitucionais.

Neste último ponto - exigência de produtos de menor impacto ambiental - não rara as vezes o Estado é omisso quanto à regulação de inúmeros setores e nichos mercadológicos existentes de produtos e serviços disponíveis para serem adquiridos e por ele utilizados, colocando em apuros os gestores públicos responsáveis pela condução de processos de contratação de bens e serviços para atender as necessidades inerentes da organização e de seus usuários e beneficiários desses serviços públicos frente a determinações de cunho legal (art. $3^{\circ}$, Lei 8.666/93) e constitucional (art. 225, CF).

Não obstante a omissão regulatória estatal, há um dever-poder do agente público nas decisões administrativas não limitado a atender aos princípios expressos no artigo 37 (legalidade, impessoalidade, moralidade, publicidade e eficiência), mas também a de garantir contratações eficientes e de qualidade nos limites - sempre que possível - daqueles disponíveis pelo mercado.

Para atender essas expectativas que otimizam os recursos humanos e financeiros empregados, deve o Estado, por intermédio de seus gestores públicos, internalizar instrumentos há tempos disponíveis no âmbito privado e que trazem resultados - como normas técnicas, gestão de riscos e compliance - e adequá-los à sua realidade organizacional 
sem, contudo, deixar de sopesar outros princípios e normas inerentes às contratações públicas - isonomia e competividade.

O presente estudo abordará, de forma sucinta e sem esgotar o tema, a ideia de sustentabilidade nas contratações públicas e tem como objetivo verificar a internalização de instrumentos de gestão disponibilizados pelo mercado privado que ensejam melhores aquisições a fim de atender aos fins pelos quais o Estado deve promover e foi concebido. $\mathrm{O}$ estudo foi desenvolvido utilizando o método dedutivo e a técnica de pesquisa utilizada foi a bibliográfica.

\section{A SUSTENTABILIDADE E A CONTRATAÇÃo PÚBLICA}

É cediço que a norma constitucional estabeleceu em seu artigo 225 que o Estado deve garantir e promover um meio ambiente equilibrado às atuais e futuras gerações de seus cidadãos, o que se extrai a ideia de que o Estado deve regular a exploração do meio ambiente para a produção de bens e serviços.

Não foi diferente a motivação infraconstitucional do legislador, ao inserir o desenvolvimento nacional sustentável no artigo $3^{\circ}$ da Lei 8.666/93, como parâmetro de exigibilidade nas contratações públicas de todas as esferas e poderes governamentais, a serem observados pelo agentes públicos que capitaneiam as organizações e entidades estatais enquanto poder-dever de suas atribuições no desenvolvimento de suas atividades.

O presente capítulo irá adentrar nas formas possíveis de sustentabilidade de acordo com as suas dimensões, tratadas pela doutrina nacional especializada, com foco nos processos e procedimentos administrativos - burocracia e praxe da Administração - a fim de delimitar a abordagem, sem olvidar esclarecer que há inúmeras outras formas de garantir compras sustentáveis.

\subsection{Dimensões da sustentabilidade e sua correlação com as contratações públicas}

Apesar do termo "sustentabilidade" ser um conceito complexo, é multidisciplinar e envolve diversas ciências (EMERY, 2016, p. 67), e na concepção de Juarez Freitas: 
solidária do desenvolvimento material e imaterial, socialmente inclusivo, durável e equânime, ambientalmente limpo, inovador, ético e eficiente, no intuito de assegurar, preferencialmente de modo preventivo e precavido, no presente e no futuro, o direito ao bem-estar. (FREITAS, 2016, p. 43)

Sobre a multidimensionalidade do bem-estar, Freitas contribui ao atentar para o fato de que se está em uma sociedade de risco mundial e não se pode mais negligenciar as consequências involuntárias das questões ambientais e que o conceito de sustentabilidade insere essa multidimensionalidade do bem-estar como opção a favor da vida. (FREITAS, 2016, p. 52).

Certo que o Estado brasileiro como um todo - instituições públicas e governo -, deve promover o bem-estar de seus cidadãos em razão de seus objetivos primeiros enquanto República - o que se depreende da leitura do artigo $3^{\circ}$ da Constituição Federal -, ensejando acesso aos bens primários, além de segurança e garantia de direitos fundamentais, como proclamado no artigo $5^{\circ}$ da Constituição Federal.

Nessa linha, não mais se admite escolhas estatais que vão de encontro a preceitos constitucionais, em especial o da sustentabilidade, tampouco nas escolhas públicas nas aquisições de bens e serviços disponíveis no mercado, respeitando sempre critérios objetivos de escolha. Valer-se dos próprios comandos normativos arrolados na lei geral de licitações como a "observância do princípio constitucional da isonomia, a seleção da proposta mais vantajosa, a promoção do desenvolvimento nacional sustentável” (art. 3º Lei 8.666/93) somados a julgamento objetivos e princípios correlatos da atuação do poder público.

Com vistas a fazer as melhores escolhas enquanto dever-poder do Estado é que deve se valer de instrumentos que tenham impactos positivos e eficientes para o bem-estar dos cidadãos, arrolando-os no instrumento convocatório quando da escolha do objeto a ser oportunamente adquirido daquele fornecedor que melhor atender aos anseios da organização estatal.

A aquisição de produtos de qualidade, não tóxicos ao meio ambiente e ao ser humano, confeccionados ou produzidos com as melhores técnicas e tecnologias disponibilizadas no mercado (industrial, serviços...) é um desafio para o gestor público, uma vez que se depara com realidades da organização - precárias ou insuficientes - e dificuldades de acesso a informações ímpares. Cite-se, por exemplo, a) a insipiência e o não compromisso do agente público de conhecer o mercado e o produto a ser adquirido; b) a ineficiência de 
dados disponíveis sobre produtos e serviços; c) a insegurança jurídica na exigibilidade de qualidade nas contratações em razão dos posicionamentos "políticos" das Cortes de Contas; d) a estrutura da organização governamental insuficiente, dentre outras situações.

A sustentabilidade possui dimensões (multidimensional ou pluridimensional) social, ética, jurídico-política, econômica e ambiental (FREITAS, 2016, p. 62) e deve o gestor público, na busca pelo fins institucionais e de interesse público, atentar para as diversas dimensões da sustentabilidade, inclusive e em especial quando contratar com particular para o fornecimento de bens e serviços.

O gestor público possui, pois, o dever-poder de buscar o melhor serviço ou produto que possa atender as suas necessidades institucionais sem infringir outros preceitos constitucionais ora já mencionados, evitando-se desperdícios de recursos públicos, de materiais, e analisar os custos diretos e indiretos quando da confecção da contratação pública.

A sustentabilidade sob a dimensão social diz respeito à proteção de direitos fundamentais sociais e que eventuais distinções se limitam a auxiliar os desfavorecidos por intermédio de ações positivas do Estado (FREITAS, 2016, p. 63). Em resumo, reclama equidade intra e intergeracional, bem como condições propícias ao desenvolvimento das potencialidades humanas (FREITAS, 2016, p. 64).

As condições propícias para o florescimento ou desenvolvimento das potencialidades humanas diz respeito às capacidades humanas, sob a ótica de Amartya Sen. Para o economista indiano, tem a ver com a visão de como uma vantagem total - ou absoluta - de que uma pessoa deve ser considerada - ou avaliada -, ou seja, "a vantagem individual é julgada pela capacidade de uma pessoa para fazer coisas que ela tem razão para valorizar” (SEN, 2011, p. 265). A priori, as capacidades têm a ver com a análise individual da pessoa, das oportunidades reais que ela dispõe, da liberdade disponibilizada para fazer ou ser aquilo que melhor lhe valorizar.

A abordagem da capacidade não se trata, obviamente, de atender as carências e necessidades básicas das pessoas, mas se concentra na função de liberdade daquilo que o ser humano poder a vir desfrutar e tem motivos próprios (sem ingerência) para valorizar (SEN, 2018, p. 68).

Partindo-se da ideia de que o núcleo da abordagem das capacidades (ou potencialidades humanas - Juarez Freitas) não se resume apenas o que uma pessoa - ou grupo - realmente faz, mas também ao que ela é capaz de fazer, decidindo em aproveitar ou não 
uma oportunidade real (SEN, 2011, p. 271), ou seja, da liberdade de escolher como viver, é que o Estado deve oportunizar por intermédio de ações e políticas públicas o desenvolvimento de capacidades considerando as variações interpessoais dos indivíduos.

Cite-se como exemplo de oportunidades para diferentes grupos econômicos pessoas jurídicas -, empresas de pequeno e grande portes, em que para aqueles lhes é oportunizado tratamento diferenciado para a comercialização de seus bens e serviços para com o Estado, mediante previsão legal em procedimento de contratação pública, para fazer frente à sua condição natural de pequena empresa e possui em princípio parcos recursos financeiros e humanos, e de gestão precária ou limitada, obviamente inferiores que em relação a empresas de grande porte, numa disputa para a oferta de um mesmo produto ou serviço ao Poder Público.

Logo, por exemplo, no ambiente de trabalho não se pode aceitar mesas, cadeiras e armários que não atendam às normas de medicina e segurança do trabalho (Norma Regulamentadora de Ergonomia NR 17 do Ministério do Trabalho), tampouco o Estado deve adquirir bens que não contemplam em sua produção tais requisitos de sustentabilidade social.

A dimensão ética da sustentabilidade, por sua vez, é alcançar o bem-estar inerente à pessoa (íntimo) e, ao mesmo tempo, o bem-estar social (FREITAS, 2016, p. 65) e o encadeamento de condutas probas éticas, reconhecendo a ligação de todos os seres e o impacto das ações e omissões do homem (FREITAS, 2016, p. 68).

É o que traz Hans Jonas quando trata da responsabilidade ao prescrever que "aja de modo a que os efeitos da tua ação sejam compatíveis com a permanência de uma autêntica vida humana sobre a Terra" (JONAS, 2011, p. 47), cuja posição ética é da responsabilidade social atual e de gerações futuras, com respeito ao meio ambiente e todas as suas formas de vida (EMERY, 2016, p. 77).

Nesse passo, o gestor público deve analisar que toda a aquisição deve ser pautada sob o prisma do amanhã, de não impactar direta ou indiretamente na saúde do homem e do meio ambiente, escolhendo produtos e serviços que tenham compromisso ético com a sustentabilidade, sem olvidar, contudo, com a isonomia e competitividade na disputa pela melhor proposta entre potenciais fornecedores.

$\mathrm{Na}$ dimensão ambiental da sustentabilidade há relação direta com o preceituado no artigo 225 da Constituição Federal, ao direito das gerações atuais e não deixar de contemplar 
ou causar prejuízo das futuras, ou seja, não se pode conceber a degradação ambiental por intermédio de ações do homem, e que não pode haver vida humana em ambiente hostil (FREITAS, 2016, p. 70).

Não é incomum estar previsto em editais de certames públicos exigências de normas ambientais, como licenças e certificados expedidos por órgãos públicos competentes, o que contribui, sob a dimensão ambiental, para uma sustentabilidade na contratação pública, a exemplo do cadastro compulsório de atividades potencialmente poluidoras ou utilizadoras de recursos ambientais, como "extração, produção, transporte e comercialização de produtos potencialmente perigosos ao meio ambiente, assim como de produtos e subprodutos da fauna e flora" (art. 17, II, Lei 6.938/81), sem olvidar, conforme o objeto contratado, a observância da legislação de saneamento (Lei $\mathrm{n}^{\circ} 11.445 / 07$ ), da política nacional de mudança climática (Lei $n^{\circ} 12.189 / 09$ ), da política nacional de resíduos sólidos (Lei $\left.{ }^{\circ} 12.305 / 10\right)$, da mobilidade urbana (Lei $\mathrm{n}^{\circ}$ 12.587/12), do código florestal (Lei $\mathrm{n}^{\circ} 12.651 / 12$ ), dentre outras, as quais devem ser implementadas de forma imediata a fim de atender ao disposto no artigo 12, VII, e outros dispositivos da Lei 8.666/93 - licitações e contratos administrativos.

A dimensão econômica da sustentabilidade concerne aos benefícios e custos diretos e indiretos, como combate ao desperdício, à economicidade (art. 70, CF) e, em suma, a "regulação do mercado aconteça de sorte a permitir que a eficiência guarde real subordinação à eficácia" (FREITAS, 2016, 72).

Nesse ponto, para melhor elucidar essa questão, relevante é o enunciado de acórdão do Tribunal de Contas da União, que assim prescreve:

É legítimo que as contratações da Administração Pública se adequem a novos parâmetros de sustentabilidade ambiental, ainda que com possíveis reflexos na economicidade da contratação. Deve constar expressamente dos processos de licitação motivação fundamentada que justifique a definição das exigências de caráter ambiental, as quais devem incidir sobre o objeto a ser contratado e não como critério de habilitação da empresa licitante. Acórdão 1375/2015 - Plenário - TCU.

A Corte de Contas da União Federal, no acórdão em tela, lança luz aos gestores públicos ao permitir que, motivadamente, exijam conduta sustentável na contratação pública e, ainda, no caso em concreto, afastou a exigibilidade de justificativas do agente público:

Ainda na representação relativa ao pregão eletrônico realizado pela Fundação Ceciliano Abel de Almeida (FCAA), destinado ao registro de preços para a prestação de serviços de impressão de material didático, o relator, ao tratar da legalidade da exigência de apresentação de certificação ambiental, ponderou que "deve constar do processo de contratação 
motivação expressa justificando a nova exigência, nos termos do art. $3^{\circ}, \S 1^{\circ}$, I, da Lei 8.666/1993, e de acordo com a jurisprudência desta Casa (Acórdão 1.687/2013-Plenário, item 9.2.2) ". Ou, em outros termos, "é legítimo que a entidade deseje adequar suas contratações a novos parâmetros de sustentabilidade ambiental, ainda que com possíveis reflexos na economicidade da compra, devendo fazer constar expressamente do processo de contratação motivação fundamentada que justifique a escolha dessas exigências". Contudo, ponderou o relator que a irregularidade não prejudicou a competitividade do certame, razão pela qual propôs, no ponto, o acolhimento das justificativas do responsável. Nada obstante, o Tribunal, à luz das demais irregularidades constatadas nos autos, considerou parcialmente procedente a representação, aplicando ao responsável a multa capitulada no art. 58, inciso II, da Lei 8.443/92, e, dentre outros comandos, cientificou a FCAA da irregularidade consubstanciada na "ausência de motivação expressa nos autos do processo de contratação para a inclusão de cláusula de exigência de apresentação de certificação ambiental, que implica em potencial aumento de custos e comprometimento da competitividade do certame, em ofensa aos arts. $2^{\circ}$, caput, e 50, da Lei 9.784/1999; o art. $3^{\circ}$, § $1^{\circ}$, I, da Lei 8.666/1993 e o Acórdão 1.687/2013-Plenário, item 9.2.2".

Pelo resumo do aludido acórdão pode-se extrair que para fins de garantir a sustentabilidade nas contratações públicas, mesmo que oriunda de comando normativo expresso, constitucional e infraconstitucional, deve o gestor público motivar sua exigibilidade em razão de sua conduta, a priori, limitar, negar ou ferir direitos ou interesses de terceiros (art. 50, I, Lei 9.784/99) ou ainda estabelecer cláusulas ou condições que comprometam, restrinjam ou frustrem o seu caráter competitivo (art. $3^{\circ}, \S 1^{\circ}$, I, da Lei 8.666/93), que não estão coadunados com o princípio constitucional da sustentabilidade.

Esse é o ponto da dimensão jurídico-política em que o sentido da sustentabilidade determina, "com eficácia direta e imediata, independentemente de regulamentação, a tutela jurídica do direito ao futuro", apresentando-se como dever constitucional, não permitindo que o Direito Administrativo seja sucumbido por omissões causadoras de danos para as atuais e futuras gerações (FRETIAS, 2016, p. 73).

O que o Tribunal de Contas da União exarou no aludido acórdão foi exatamente a extensão da dimensão jurídico-política defendida por Juarez Freitas, ao corroborar - naquele caso - com o entendimento do gestor público de dispensar a justificativa de exigências sustentáveis nos processos licitatórios, apesar de recomendar, com base nos dispositivos legais supramencionados, que nos futuros certames haja motivação dos atos a fim de atender aos ditames da legislação administrativa e de contratos públicos. 
Pode-se perceber que as exigências para a busca de contratações sustentáveis se limitaram àquelas de caráter normativo legal, ou seja, oriunda da lei em sentido estrito, não contemplando normas técnicas ou outras normatizações internacionais que deveriam ser levadas em consideração pelos agentes do Estado, o qual será abordado no próximo capítulo do presente estudo.

\subsection{A sustentabilidade nas contratações públicas}

Para o presente estudo, importante destacar que a expressão "contratações públicas" compreende os processos e procedimentos de licitação e do contrato, ou seja, o procedimento licitação que é prévio à realização do contrato (TORRES, 2018, p. 44) e o contrato administrativo em si, sem olvidar as dispensas e inexigibilidade de licitação previstos nos artigos 24 e 25 da Lei $\mathrm{n}^{\circ} 8.666 / 93$.

$\mathrm{Na}$ praxe administrativa são muitas as normas em que o agente público deve obedecer, sejam elas procedimentais ou não, reguladoras ou não, e, recentemente, foi editado o novo Decreto do Pregão, o Decreto n ${ }^{\circ}$ 10.024/2019, que estabeleceu, dentre outras diretrizes administrativas, o princípio do desenvolvimento sustentável, o qual deve ser observado em várias etapas do processo em si. $\mathrm{O}$ artigo $2^{\circ}$ e $\S \S 1^{\circ}$ e $2^{\circ}$ assim prescrevem:

Art. $2^{\circ} \mathrm{O}$ pregão, na forma eletrônica, é condicionado aos princípios da legalidade, da impessoalidade, da moralidade, da igualdade, da publicidade, da eficiência, da probidade administrativa, do desenvolvimento sustentável, da vinculação ao instrumento convocatório, do julgamento objetivo, da razoabilidade, da competitividade, da proporcionalidade e aos que lhes são correlatos.

$\S 1^{\circ} \mathrm{O}$ princípio do desenvolvimento sustentável será observado nas etapas do processo de contratação, em suas dimensões econômica, social, ambiental e cultural, no mínimo, com base nos planos de gestão de logística sustentável dos órgãos e das entidades.

$\S 2^{\circ}$ As normas disciplinadoras da licitação serão interpretadas em favor da ampliação da disputa entre os interessados, resguardados o interesse da administração, o princípio da isonomia, a finalidade e a segurança da contratação.

Mais uma vez - apesar de sua competência ser apenas no âmbito do governo federal, salvo a exceção do artigo $1^{\circ}, \S 3^{\circ}$ - estabeleceu-se um comando normativo a fim de ensejar atendimento à norma constitucional da sustentabilidade e contemplando todas as suas dimensões - aqui tratadas -, o que corrobora com práticas administrativas necessárias para o atendimento dos fins com resultado e eficiência. 
Aplicar as dimensões da sustentabilidade nas contratações públicas não parece ser tarefa inalcançável, até porque no cotidiano administrativo dos setores de compras ocorrem, seja por determinação legal, seja por convenções ou conveniências internas, práticas sustentáveis pouco percebidas pelos agentes públicos, compreendidas muito mais como meio de facilitar e otimizar os procedimentos laborais do que sopesar a ideia de eficiência sustentável, mas não quer isso dizer que a prática - sem consciência ambiental - não atenda as dimensões aqui tratadas.

Muitos dos procedimentos são oriundos de previsão legal, tidas como facultativas, mas pouco utilizadas na prática até porque são consideradas pelas Cortes de Contas, a exemplo do TCU, ora benéfica ora como afronta aos princípios da competitividade e da isonomia nos certames licitatórios, o que pode, a priori, ir de encontro com uma ou mais dimensões da sustentabilidade.

Como modelo adotado pela praxe administrativa, a utilização da compra compartilhada, oriunda do sistema de registro de preços autorizada pelo inciso II, do artigo 15, da Lei ${ }^{\circ} 8.666 / 93$, é aquela que permite que outros órgãos públicos se vinculem ao órgão gerenciador de determinado certame com vistas à aquisição de um mesmo objeto, contribuindo para a diminuição de processos, concentração de compras, economia de escala e celeridade processual.

O governo federal regulamentou o dispositivo legal em comento ao promulgar decretos que tratam do tema, hodiernamente vigente o Decreto $n^{\circ} 7.892 / 13^{*}$, que trouxe

\footnotetext{
*Art. $2^{\circ}$ Para os efeitos deste Decreto, são adotadas as seguintes definições:

I - Sistema de Registro de Preços - conjunto de procedimentos para registro formal de preços relativos à prestação de serviços e aquisição de bens, para contratações futuras;

II - ata de registro de preços - documento vinculativo, obrigacional, com característica de compromisso para futura contratação, em que se registram os preços, fornecedores, órgãos participantes e condições a serem praticadas, conforme as disposições contidas no instrumento convocatório e propostas apresentadas;

III - órgão gerenciador - órgão ou entidade da administração pública federal responsável pela condução do conjunto de procedimentos para registro de preços e gerenciamento da ata de registro de preços dele decorrente; IV - órgão participante - órgão ou entidade da administração pública que participa dos procedimentos iniciais do Sistema de Registro de Preços e integra a ata de registro de preços; (Redação dada pelo Decreto ${ }^{\circ}$ 8.250, de 2.014)

V - órgão não participante - órgão ou entidade da administração pública que, não tendo participado dos procedimentos iniciais da licitação, atendidos os requisitos desta norma, faz adesão à ata de registro de preços.

VI - compra nacional - compra ou contratação de bens e serviços, em que o órgão gerenciador conduz os procedimentos para registro de preços destinado à execução descentralizada de programa ou projeto federal, mediante prévia indicação da demanda pelos entes federados beneficiados; e (Incluído pelo Decreto ${ }^{\circ} 8.250$, de 2.014)
} 
importantes definições, as quais contemplam de certa forma as dimensões da sustentabilidade, como a de Sistema de Registro de Preços; ata de registro de preços; órgão gerenciador; órgão participante - órgão não participante; compra nacional; órgão participante de compra nacional.

Ainda pelo regulamento federal, o Sistema de Registro de Preços torna facultativa ao gestor público adotá-lo nas seguintes hipóteses, nos termos do seu artigo $3^{\circ}$ :

I - quando, pelas características do bem ou serviço, houver necessidade de
contratações frequentes;
II - quando for conveniente a aquisição de bens com previsão de entregas parceladas
ou contratação de serviços remunerados por unidade de medida ou em regime de
tarefa;
III - quando for conveniente a aquisição de bens ou a contratação de serviços para
atendimento a mais de um órgão ou entidade, ou a programas de governo; ou
IV - quando, pela natureza do objeto, não for possível definir previamente o
quantitativo a ser demandado pela Administração.

Apesar da facultatividade do legislador em oportunizar ao gestor público utilizar-se do sistema de registro de preços para suas aquisições - sem adentrar em demasiado nas peculiaridades e benefícios do mecanismo - o gestor público tem dever legal pelo princípio constitucional da sustentabilidade em aderir sempre que possível ao procedimento - instituí-lo como regra -, ressalvadas as condições inerentes e devidamente justificadas nos autos da futura aquisição para sua não utilização. É o entendimento corroborado por Ronny Charles Lopes de Torres ao prescrever que:

[...] sendo o SRP (sic) um instrumento que gera maior eficiência nas contratações públicas aptas a sua utilização, não parece admissível que o gestor público, o qual deve escolher sempre a melhor opção para o atendimento do interesse público (e não de seu interesse privado), abdique da melhor opção por desídia, incúria ou vontade íntima. (TORRES, 2018, p. 173)

Não obstante a facultatividade legal, num exemplo de posicionamento que contempla a sustentabilidade o Tribunal de Contas da União em uma decisão ditou ser obrigatória a utilização do sistema de registro de preços sempre que for cabível, nos termos do Acórdão 378/2011 - Plenário, referindo-se ao Informativo $n^{\circ} 21$ dessa Corte de Contas, ao prescrever que "fere o sentido teleológico da referida norma interna, além de contrariar o senso comum

VII - órgão participante de compra nacional - órgão ou entidade da administração pública que, em razão de participação em programa ou projeto federal, é contemplado no registro de preços independente de manifestação formal. (Incluído pelo Decreto $\mathrm{n}^{\circ} \mathrm{8.250}$, de 2.014) 
do administrador médio, dispensar a utilização de um sistema de aquisição de bens e serviços que se revela mais econômico e eficiente". Eis o resumo do acórdão, com grifos originais:

Contratação no âmbito dos serviços sociais autônomos: 2 Obrigatoriedade de utilização do sistema de registro de preços quando presentes as condições para a sua adoção

Tendo em conta o princípio da eficiência da administração pública, insculpido no caput do art. 37 da Constituição Federal, é poder-dever do Serviço Social do Comércio a utilização do sistema de registro de preços quando estiverem presentes as condições para a sua implantação. Foi esse o entendimento defendido pelo relator, ao apreciar recurso de reconsideração interposto pelo Serviço Social do Comércio/Administração Regional do Acre (SESC/AC) contra a seguinte determinação que lhe foi expedida mediante o Acórdão no 2.210/2009-1 ${ }^{\text {a }}$ Câmara: 'passe a adotar, quando da necessidade de aquisição de bens e serviços de forma frequente, como ocorre em relação à reposição de estoques de gêneros alimentícios não perecíveis e perecíveis, o Sistema de Registro de Preços, conforme previsto no art. 33, inciso II, da Resolução 1102/2006, que aprovou o Regulamento de Licitações e Contratos do Serviço Social do Comércio, de forma a obter preços mais vantajosos para a administração.'. Em sua instrução, a unidade técnica propôs o provimento parcial do recurso, a fim de converter, em recomendação, a determinação formulada ao SESC/AC, no sentido de utilizar o sistema de registro de preços para aquisição de bens e serviços contratados de forma frequente. Em seu voto, o relator destacou que a tese perfilhada pelo recorrente, no sentido de o regulamento do SESC não impor a obrigatoriedade de utilização do registro de preços, mesmo quando presentes as condições para a adoção do referido sistema, assenta-se, basicamente, numa interpretação estrita e literal do art. 33 do Regulamento de Licitações e Contratos do SESC (Resolução $\mathbf{n}^{\circ}$ 1.102/2006), que assim dispõe: 'Art. 33. O registro de preços, sempre precedido de concorrência ou de pregão, poderá ser utilizado nas seguintes hipóteses [...].' Para o relator, tal exegese limitativa contraria, além da finalidade da própria norma interna do Serviço Social do Comércio, o princípio da eficiência contido no caput do art. 37 da Constituição Federal. 'Fere o sentido teleológico da referida norma interna, além de contrariar o senso comum do administrador médio', dispensar a utilização de um sistema de aquisição de bens e serviços que se revela mais econômico e eficiente para o Sistema $s$, quando presentes os requisitos estabelecidos nos incisos I a III do art. 33 da Resolução Sesc $n^{0} 1.102 / 2006$. Segundo o relator, a melhor interpretação que se pode emprestar ao sentido da palavra 'poderá', inscrita no caput do art. 33 do referido regulamento, é a de 'poder-dever', de sorte a harmonizar a finalidade da norma com os parâmetros diretores da administração pública, a reclamar uma atuação cada vez mais eficiente dos entes de colaboração. Ao final, o relator propôs e a Primeira Câmara decidiu negar provimento ao recurso. Precedente citado: Acórdão no 324/2009-Plenário. Acórdão n ${ }^{0}$ 3493/2010-1 ${ }^{a}$ Câmara, TC 019.680/2009-2, rel. Min. Walton Alencar Rodrigues, 15.06.2010. (grifos nossos) 
Contribuindo com os ensinamento de Juarez Freitas, Marçal Justen Filho, ao comentar acerca do sistema de registro de preços, prescreve que quando da aplicação direta a lei na ausência de regulamento incumbe ao intérprete "verificar a possibilidade de aplicação direta dos dispositivos legais", superando-se o texto legislativo e aplicando a lei, apesar de advertir que em alguns tópicos necessita de prévia regulamentação (JUSTEN FILHO, 2019, p. 311), corroborando de que é dever do gestor público atender os preceitos legais e constitucional no exercício de suas atribuições na busca do interesse público.

Há outros procedimentos possíveis de serem adotados para assegurar contratações eficientes e sustentáveis, como o princípio da padronização (art. 15, I, da Lei n 8.666/93), a amostra de produtos - apenas com previsão jurisprudencial -, a exigência de laudos dos produtos, a divisibilidade do objeto (art. 15, IV, da Lei $n^{\circ}$ 8.666/93), a identificação de marca - com as ressalvas jurisprudenciais -, a adesão tardia (comumente conhecida como carona) previsto no artigo 22 do Decreto ${ }^{\circ} 7.892 / 13$, a exigência de cumprimento de padrões oficiais como selos, certificações e normas técnicas, a gestão de riscos, os quais visam qualidade nos objetos a serem adquiridos, sendo estes últimos tópicos objeto de análise no próximo capítulo.

\section{GESTÃO DE RISCOS E NORMAS TÉCNICAS NAS CONTRATAÇÕES PÚBLICAS}

Muito se discute acerca da possibilidade ou não de se valer o Poder Público de normas técnicas nos procedimentos licitatórios, tendo em vista os ditames legais extraídos dos artigos 27 a 31 da Lei 8.666/93 interpretados pelas Cortes de Contas, em especial quando não são compulsórias por exigência legal, apesar de, nos últimos tempos, o Governo Federal emitiu regramentos acerca da gestão de riscos como instrumento de Governança Pública - e como governança na contratação (artigo $2^{\circ}$, IV, Decreto 9.203/17).

Sabe-se que para a gestão de riscos há vários standards, como a norma ISO $31000 / 2018$, que fornece princípios e diretrizes gerais de gestão de riscos aplicadas a qualquer empresa ou setor (ABNT, 2019, on-line), bem como o ERM COSO (Enterprise Risk Management - Gestão de Riscos Corporativos), que é uma metodologia criada para identificar riscos gerais da organização (GIOVANINI, 2014, p. 62).

\subsection{Normas técnicas como instrumento de eficiência e sustentabilidade}


Benoit Frydman adverte quanto à legitimidade das normas técnicas, prescrevendo que elas possuem "caráter puramente voluntário e consensual" e "não trariam problema de legitimidade, desde que ninguém fosse obrigado a segui-los, ao contrário, pertence a cada um decidir livremente e positivamente adotar e respeitar um standard” (2018, p. 82). Continua dizendo que "não é preciso tratar o standard como uma fonte formal do Direito, que ele não é, mas considerar mais, de um ponto de vista pragmático, os efeitos de regulamento que ele produz" (2018, p. 83).

Logo, não sendo as normas técnicas exigíveis para fins de atender aos mecanismos que a legislação estabelece - a priori deveria ser regras sob o enfoque o princípio constitucional da sustentabilidade -, as empresas, na prática, buscarão se valer dessas diretrizes normativas para assegurar que os procedimentos adotados atendem a uma norma que possua um padrão e sejam reconhecidas por outras empresas e "passam a ter maior poder de competitividade no mercado externo" (FOIATTO, 2018, p. 43).

As práticas adotadas pelo mercado privado - utilização de normas técnicas nacionais e internacionais, ISO, ABNT etc - deveriam servir de exemplo para que a Administração Pública se valesse dessa disputa sadia, ao buscar nele as melhores prática não apenas na sua organização interna - como está a fazer com a instituição da governança pública e gestão de riscos - mas também para aquisição de bens e serviços, usufruindo-se dos benefícios da competitividade privada.

Todavia, aos olhos dos órgãos de controle externo tais condutas ferem a isonomia estabelecida pelo artigo $3^{\circ}$ da Lei $n^{\circ} 8.666 / 93$ - assim como o artigo 37, XXI, da CF entre os participantes da disputa, mas a própria lei abre exceção ao permitir que se contratem, como critério de preferência, "produtos manufaturados e para serviços nacionais que atendam a normas técnicas brasileira", não como regra, mas faculdade.

Por outro lado, o Decreto $\mathrm{n}^{\circ} 7.746 / 12$, que regulamenta o art. $3^{\circ}$ da Lei $\mathrm{n}^{\circ}$ 8.666/93, para estabelecer critérios e práticas para a promoção do desenvolvimento nacional sustentável nas contratações - competência apenas da administração pública federal - estabeleceu em seu artigo $4^{\circ}$ critérios e práticas consideradas sustentáveis, como rol exemplificativo, dentre elas origem sustentáveis dos recursos naturais (seu inciso VIII), maior eficiência na utilização de recursos naturais e maior vida útil e menor custo (incisos 
III e IV), para citar alguns exemplos, além de permitir a comprovação das exigências por meio de certificação emitida ou reconhecida por instituição pública oficial ou instituição credenciada ou por outro meio definido no certame (art. $8^{\circ}$ ).

Nessa linha, não é vedada a utilização de certificações expedidas por órgãos ou entidades nacionais, tampouco internacional - porque a norma não a veda expressamente como ISO e as NBR. A exemplo da ISO 14.000, que especifica um sistema de gestão ambiental aplicável a qualquer organização (público ou privada), permitindo-se que se exija essa certificação a todos os contratos, sejam eles de grande, médio ou pequeno porte, inclusive do próprio governo (EMERY, 2016, p. 71), com o intuito de cumprir as dimensões do princípio da sustentabilidade.

Para Jair Eduardo Santana "não há no ordenamento jurídico a exigência de certificados tais como ISO, ABNT, INMETRO, ABIC ou qualquer outra certificação onerosa, para a produção de algum bem ou para o exercício de alguma atividade". Contudo, aduz ser possível exigir certificado da série ISO ou outra certificação onerosa como julgamento de proposta técnica - critério de julgamento melhor técnica e preço. (SANTANA, 2016, p. 76)

Contudo, acerca da utilização de normas técnicas da Associação Brasileira de Normas Técnicas (ABNT), o posicionamento do autor é mais flexível, mas adverte que não é o mesmo que a exigências de certificação expedida por esta entidade não governamental, tendo em vista a expedição de certificação ser opcional, mas o cumprimento das normas expedidas pelo órgão é obrigatória (SANTANA, 2016, p. 77).

A inserção de normas técnicas no âmbito das contratações públicas, em resumo - e para não adentrar em minúcias que esse tema ricamente propõe (entendimento doutrinário e do controle externo) -, deve-se pautar pela razoabilidade e necessidade de atendimento do interesse público, e colacionando a contribuição de Eduardo Fortunato Bim, salutar para esse debate, ao prescrever que:

Não é porque aparentemente um sistema de certificação é bom para o meio ambiente que o Estado deve incorporá-lo a qualquer preço nas compras governamentais. A existência de ato normativo prevendo os critérios é fundamental. A norma não prevê o tipo de certificação, mas os requisitos que devem ser certificados, ainda que eles integrem alguma certificação em especial.

Para que a exigência desses certificados não seja arbitrária, não decorra do mero apreço do gestor por um sistema certificatório qualquer e que não configure uma estatização caprichosa de algum padrão privado discutível, é imperativo, no mínimo, ato geral na Administração Pública que o preveja ou, quando a sua adoção for particularizada, justificação técnica. Essa previsão, 
frise-se, deve ocorrer em relação aos requisitos, uma vez que ninguém poderia ser obrigado a obter a certificação X ou Y, mas apenas a cumprir os seus requisitos (BIM, 2015, p. 197).

Logo, o gestor público quando da elaboração de editais licitatórios visando o cumprimento das disposições legais e do princípio constitucional da sustentabilidade, deve-se atentar, primeiramente, aos ditames da Constituição Federal e o entendimento do respectivo tribunal de contas, assim como as diretrizes estabelecidas pelo Tribunal de Contas da União, e respaldado pela doutrina especializada e pessoal técnico conhecedor do objeto a ser adquirido.

\subsection{Gestão de riscos e sua contribuição para sustentabilidade nas contratações públicas}

O governo federal estabeleceu a gestão de riscos no âmbito da organização pública, ao prescrever como objetivos da gestão de riscos de assegurar aos responsáveis pelas tomada de decisão acesso a informações quanto aos riscos a que a organização está exposta e aumentar as chances de alcançar os objetivos da organização (IN MP/CGU 01/2016, art. 15, I e II).

Tal afirmação legal corrobora com o entendimento de Amartya Sen que "a adequação de um sistema de accountability não pode ser dissociada dos objetivos que estão sendo perseguidos" (SEN, 2015, p. 141), ou seja, a entidade ou organização pública deve criar mecanismos de controle, responsabilidades de seus agentes e prestação de contas condizentes com os fins a que ela foi concebida - o que inclui os preceitos da sustentabilidade aqui defendido.

Quanto à gestão de riscos, importante trazer algumas questões para melhor o entender. $\mathrm{O}$ gerenciamento de riscos é "a capacidade de uma organização de gerenciar incertezas", positiva ou negativa, que "consegue antecipar o maior número de eventos incertos", "é entender como identificar o risco, priorizar e tratar os eventos encontrados" (CASTRO, 2018, p. 48).

A citada instrução normativa trouxe a ideia de compliance em seu artigo $6^{\circ}$, sem, contudo, conceitua-lo. Acrescenta-se a este estudo o conceito que melhor traduz o termo Compliance, elaborado por Ana Frazão, que o conceitua como "ao conjunto de ações a serem adotadas no ambiente corporativo para que se reforce anuência da empresa à legislação 
vigente, de modo a prevenir a ocorrência de infrações ou, já tendo ocorrido o ilícito, propiciar o imediato retorno ao contexto de normalidade e legalidade” (FRAZÃO, 2007, p. 42).

O compliance que diz respeito à integridade está intrinsicamente ligada ao desenvolvimento sustentável por inúmeras razões, dentre as quais, "a sustentabilidade deve ser analisada de forma holística, inclusive, de acordo com os ditames da integridade" (CASTRO, 2019, p. 29).

Poder-se-ia por uma leitura apressada afirmar que governança pública, compliance e accountability terem o mesmo sentido, o que se demonstra um equívoco. Para fins didáticos, importante transcrever o que os diplomas e instruções legais definem acerca desses conceitos.

Conforme dispõe o Decreto 9.203/2017, governança pública é “conjunto de mecanismos de liderança, estratégia e controle postos em prática para avaliar, direcionar e monitorar a gestão, com vistas à condução de políticas públicas e à prestação de serviços de interesse da sociedade" (Decreto 9.203/2017, artigo $2^{\circ}$, I).

O disposto nesse regulamento federal não é um fim em si mesmo, isto é, não é um conceito acabado, mas um ponto de partida como referencial para toda a Administração Pública Federal, "com a indicação de um conjunto inicial de referências de boas práticas e a delimitação de um objetivo". De forma mais sucinta, o guia do governo orienta que governança pública "compreende tudo o que uma instituição pública faz para assegurar que sua ação esteja direcionada para objetivos alinhados aos interesses da sociedade" (CASA CIVIL, 2018, p. 15-16).

Outro conceito que decorre a governança pública e não dispensa citação é o de governança corporativa. O Instituto Brasileiro de Governança Corporativa - IBGC formula a seguinte definição:

Governança corporativa é o sistema pelo qual as empresas e demais organizações são dirigidas, monitoradas e incentivadas, envolvendo os relacionamentos entre sócios, conselho de administração, diretoria, órgãos de fiscalização e controle e demais partes interessadas. As boas práticas de governança corporativa convertem princípios básicos em recomendações objetivas, alinhando interesses com a finalidade de preservar e otimizar o valor econômico de longo prazo da organização, facilitando seu acesso a recursos e contribuindo para a qualidade da gestão da organização, sua longevidade e o bem comum (IBGC, online).

Em apertada síntese conclusiva em trabalho desenvolvido por Edimur Ferreira de Faria, quanto ao conceito de governança corporativa aplicado ao setor público, estabelece ser 
“o modelo de administração indicado para promover os princípios da boa governança no Brasil, a fim de perquirir a efetividade e eficiência na solução de questões sociais, em que se aplicam: probidade, informação, publicidade, accountability e eficiência estatal” (FARIA, 2019).

Para Marinês Restalatto Dotti, a governança contribui para eficiência nas contratações públicas - que é intrínseca à sustentabilidade - onde se entende

[...] fundamental que sejam implementadas ações potencialmente inibidoras de atos contrários à ordem jurídica, com supedâneo na normatização e principiologia existentes, por meio da aplicação de medidas jurídicoadministrativas no âmbito da governança de organizações e de seus processos de licitação e contratação (DOTTI, 2018, p. 145).

Por intermédio da gestão de riscos o Estado consumidor poderá antever e, por consequência, fazer com o que o mercado privado se adeque às exigências de sustentabilidades impostas pelo Estado enquanto promotor do bem-estar social de todos, nos termos exigíveis pela Constituição Federal.

\section{CONSIDERAÇÕES FINAIS}

Conceber a sustentabilidade como princípio constitucional enquanto diretriz para a Administração Pública não é uma tarefa fácil para a doutrina especializada, tampouco para o gestor público, que nos inúmeros procedimentos e rotinas que a praxe administrativa lhe exigem diariamente não terá condições - nem discernimento plausível - para ensejar aplicação das diretrizes da sustentabilidade, em especial na contratação pública.

Como verificado, são demasiadas e complexas as leis esparsas a que deve atenção o administrador público, inclusive de responsabilização, além das ceifadas capitaneadas pelos órgãos de controle que de certa forma atenuam a exigibilidade da sustentabilidade em suas dimensões perante a Administração Pública, ainda na visão "arcaica" do direito administrativo - mais sancionador e disciplinador do que regulador ou eficiente - que deve contemplar preponderantemente os princípios da legalidade sobre o da eficiência, da proporcionalidade, da razoabilidade, e, agora, os da governança pública, que inclui, dentre outros, integridade e melhoria regulatória. 
Todavia, ao mesmo tempo que ao Estado interessa em regular o princípio constitucional da sustentabilidade no âmbito de sua praxe administrativa, é de se ter em mente que, além dos mecanismos disponíveis - como governança, compliance, gestão de riscos -, outras boas práticas não normatizadas pelo direito devem ser implementadas mesmo sem regulamentação, pois o princípio constitucional é diretriz para as tomadas de decisões de órgãos e entidades públicas, que serve de guia para o administrador público.

A utilização de normas técnicas nacionais e/ou internacionais contribuem para contratações eficientes, tendo em vista que os bens e serviços a serem adquiridos possuem um selo de qualidade atestada e garantida por setores especializados de determinado nicho de mercado, passando pelo crivo de boas técnicas e práticas para serem filtrados no âmbito de outros produtos e serviços similares.

Como acertadamente verificado junto à doutrina de Juarez Freitas, não há mais espaço para deixar para o amanhã - ou mediante custosa e morosa regulamentação em cada ente federado - a aplicação do princípio constitucional da sustentabilidade em suas dimensões, pois é dever inerente do Estado por seu gestor público a sua implementação, com base nas diretrizes e princípios constitucionais que asseguram uma boa Administração Pública em prol do direito ao futuro sustentável.

\section{REFERENCIAS}

ABNT. Gestão de Riscos. Disponível em: http://www.abnt.org.br/imprensa/releases/5753lancada-a-nova-versao-da-norma-iso-31000-gestao-de-riscos Acesso em: 29 dez. 2019.

BOFF, Salete Oro; CALEGARI, Cassiano. E-Governos: da utopia à distopia. Revista Da Faculdade De Direito Da Uerj, v. 29, p. 49-54, 2016.

ZAMBAM, Neuro J. A compreensão de sustentabilidade para uma política de desenvolvimento a partir da teoria de Rawls. Revista Brasileira de Estudos Políticos, v. 1, p. 215-239, 2013.

SOUZA, Liege A.; STAHLHOFER, Iásin S. Avaliação das políticas públicas brasileiras de persecução ao cumprimento dos objetivos de desenvolvimento do milênio. São Paulo: Letras Jurídicas, 2015. v. 1.

BRASIL. Constituição da República Federativa do Brasil de 1988. Disponível em: http://www.planalto.gov.br/ccivil_03/constituicao/constituicao.htm. Acesso em 29 dez. 2019.

BRASIL. Decreto ${ }^{\circ} 7.746 / 2012$. Regulamenta o art. $3^{\circ}$ da Lei $n^{\circ} 8.666$, de 21 de junho de 1993, para estabelecer critérios e práticas para a promoção do desenvolvimento nacional 
sustentável nas contratações realizadas pela administração pública federal direta, autárquica e fundacional e pelas empresas estatais dependentes, e institui a Comissão Interministerial de Sustentabilidade na Administração Pública - CISAP. (Redação dada pelo Decreto n ${ }^{\circ}$ 9.178, de 2017). Disponível em: http://www.planalto.gov.br/ccivil_03/_Ato20112014/2012/Decreto/D7746.htm. Acesso em 29 dez 2019.

BRASIL. Lei ${ }^{\circ}$ 8.666/1993. Regulamenta o art. 37, inciso XXI, da Constituição Federal, institui normas para licitações e contratos da Administração Pública e dá outras providências. Disponível em: http://www.planalto.gov.br/ccivil_03/leis/18666cons.htm. Acesso em $29 \mathrm{dez}$ 2019.

BRASIL. Decreto 9.203/2017. Dispõe sobre a política de governança da administração pública federal direta, autárquica e fundacional. Disponível em: http://www.planalto.gov.br/ccivil_03/_ato2015-2018/2017/decreto/D9203.htm. Acesso em 29 $\operatorname{dez} 2019$.

BRASIL. Decreto 7.892/2013. Regulamenta o Sistema de Registro de Preços previsto no art. 15 da Lei $\mathrm{n}^{\mathrm{o}}$ 8.666, de 21 de junho de 1993. Disponível em: http://www.planalto.gov.br/ccivil_03/_ato2011-2014/2013/decreto/d7892.htm. Acesso em 29 $\operatorname{dez} 2019$.

BRASIL. Ministério do Planejamento Orçamento e Gestão. Instrução Normativa Conjunta MP/CGU 01/2016. Dispõe sobre controles internos, gestão de riscos e governança no âmbito do Poder Executivo federal. Disponível em: http://www.in.gov.br/materia//asset_publisher/Kujrw0TZC2Mb/content/id/21519355/do1-2016-05-11-instrucao-normativaconjunta-n-1-de-10-de-maio-de-2016-21519197 Acesso em: 23 ago. 2019.

CASTRO, Rodrigo Pironti Aguirre de; GONÇALVES, Francine Silva Pacheco. Compliance e gestão de riscos nas empresas estatais. Belo Horizonte: Fórum, 2018.

- Compliance nas contratações públicas: exigências e critérios normativos. Belo Horizonte: Fórum, 2019.

ISO 14001. Sistema de Gestão Ambiental. Disponível em: https://certificacaoiso.com.br/iso14001/. Acesso em: 29 dez. 2019.

EMERY, Emerson Baldotto. Desenvolvimento sustentável: princípio da eficiência em procedimentos licitatórios. Belo Horizonte: Fórum, 2016.

FARIA, Edimur Ferreira de; DAMASCENO, Luíza Mascarenhas. Governança Corporativa na Administração Pública. Revista de Direito Administrativo e Infraestrutura, São Paulo, vol. 8/2019, p. 153 - 169, Jan - Mar 2019. Online. Acesso em: 25 ago. 2019.

FOIATTO, Ana Regina. Regulamentação internacional e brasileira do compliance. In: TOMAZ, Roberto Epifanio. Descomplicando o compliance. Florianópolis: Tirant Lo Blanch, 2018.

FREITAS, Juarez. Sustentabilidade: direito ao futuro. 3. ed. Belo Horizonte: Fórum, 2016. 
FRYDMAN, Benoit. O fim do estado de direito: governar para standards e indicadores. 2. ed. Porto Alegre: Livraria do Advogado, 2018.

GIOVANINI, Wagner. Compliance: a excelência na prática. São Paulo: [s.e], 2014.

JUSTEN FILHO. Marçal. Comentários à lei de licitações e contratos administrativos: Lei 8.666/1993. 18. ed. rev., atual. e ampl. São Paulo: Thompson Reuters Brasil, 2019.

SANTANA, Jair Eduardo; CAMARÃO, Tatiana; CHRISPIM, Anna Carla Duarte. Termo de referência: o impacto da especificação do objeto e do termo de referência na eficácia das licitações e contratos. 5. ed. Belo Horizonte: Fórum, 2016.

SEN, Amartya. A ideia de justiça. Tradução de Ricardo Doninelli Mendes Laila Coutinho. São Paulo: Companhia das Letras, 2011.

; DRÈZE, Jean. Glória incerta: a Índia e suas contradições. Tradução de Ricardo Doninelli Mendes Laila Coutinho. São Paulo: Companhia das Letras, 2015, on-line.

STAFFEN, Marcio. Superlegality, global law and the transnational corruption combat. Revista Brasileira de Direito, Passo Fundo, vol. 14, n. 1, p. 111-130, Jan.-Abr., 2018.

TORRES, Ronny Charles Lopes de. Leis de licitações públicas comentadas. 9. ed. Salvador: Ed. Juspodivm, 2018. 